\title{
DETERMINANTS OF PRODUCTIVITY IMPROVEMENT - AN EMPIRICAL STUDY
}

\author{
T.B.Pankhania ${ }^{1}$, A.H.Jariya ${ }^{2}$, V.K.Modi ${ }^{3}$ \\ ${ }^{1}$ Associate Professor in Mechanical Engineering and Head, Workshop, B.V.M.Engineering College, Sardar Patel \\ University, Vallabh Vidyanagar, Gujarat, India, tbp@sify.com \\ ${ }^{2}$ Assistant Professor in Production Engineering, B.V.M.Engineering College, Gujarat Technological University, \\ Ahmadabad, India,jariya_akil@yahoo.com \\ ${ }^{3}$ Lecturer, Mechanical Engineering Department, $B . \& B$. Institute of Technology, Vallabh Vidyanagar, Gujarat \\ Technological University, Ahmadabad, India, modi_vint@yahoo.com
}

\begin{abstract}
This paper reads about various factors that affect employees' productivity. The survey was conducted to know the opinions of employees about their views regarding the factors which are helpful in improving industrial performance. Exploratory factor analysis uncovers the predominant factors influencing industrial performance and hence productivity. It has been widely accepted that employees play vital role in improving industrial scenario in the highly competitive businesses in global arena. Motivated and satisfied workers will work with more efficiency and effectively to bring out maximum possible acceptable outputs, more revenue generated boost living standard of the people of especially under developed, developed nations
\end{abstract}

Keywords: Attitude, boss, case, communality, factor, feel good, model, performance, productivity

\section{INTRODUCTION}

To make employees more productive the following aspects must be considered for improving organizations productivity [05]:

Attitude: Happy employees are more productive. An employee with a positive attitude usually enjoys the work that they do and feels empowered and recognized for their contributions, hence an attitude is everything.

Boss: An employee's productivity is determined by their relationship with immediate supervisor. When promises are turned down, no credit though due, Makes negative comments or blames others for their mistakes, the productivity level of their employees is significantly impacted. "A poor supervisor is definitely the No.1 factor that causes low productivity," said Barry L. Brown, President of a Florida - based consulting group. A good supervisor will motivate, inspire, encourage and reward good performance. A poor supervisor, of course, is just the opposite, hence boss is the barrier.

Health: Health concerns, naturally, are a big drain on an employee's ability to be productive, and companies know it. In Washington, D.C., a survey showed that 85 percent of U.S. employees said they were interested to increase employee productivity, minimize absences and enhance the health of their employees.
Technical Tools: All the feel good, psychological methods of improving employees' productivity are great, but they are useless without the right tools. And the right tools mean the right technology. For an employee to be efficient and productive in today's job environment-global scenario means equipping employees with the right gear. Companies that do not upgrade or ignore the necessity for tech tools, and those do not adopt change will fail measurably face diminished employee productivity.

Downsizing and Outsourcing: Downsizing is expensive labor while outsourcing a cheaper version. For employees remaining in those offices and factories, their morale and motivation can take a big hit. In most cases, employers fail to recognize that if they downsize or outsource, they need to provide support to the employees that remain. The psychological impact on employees can directly impact productivity, forcing many to focus on their second careers instead of the job at hand.

Thus, employees play vital role to improve industrial performance of the organizations.

\section{THE CASE}

The research was carried out at Vitthal Udyognagar in Anand district of Gujarat state. The study was targeted to the lower level employees, mainly workers. It was aimed to know the perceptions of the workers from the representative industries of the sample considered. Total 150 questionnaires were 
distributed among the respondents. Out of 150, 85 questionnaires were omitted due to incomplete, inconsistent and irrelevant responses. Hence sample of size 65 was considered for the study. These responses include primary data from small, medium and large scale units in operation. These responses were considered from usable questionnaires only and responses were $43.33 \%$ which were considered acceptable for this research study and analysis. The five point Likert scale: Strongly agree (05), Agree (04), Not sure (03), Disagree (02) and strongly disagree (01) was used.

\section{RESEARCH METHODOLOGY}

The basic methodology that followed was the questionnaire method. To serve the purposes, the researchers has designed questionnaire, the instrument was designed to gain the maximum relevant information from the lower level employees of the organisation. It is a road map of the collection, measurement and analysis of data. For this research study both the primary and secondary sources of data were used [4, 6-7].

\section{STATISTICAL ANALYSIS}

Statistical Software was used to carry out various tests using SPSS17.0. Statistical Inferences:

Reliability Test: The questionnaire is reliable with cronbatch's alpha $(\alpha)=0.788$ and it can be used for statistical analysis as $\alpha=0.70$ is acceptable [04].

Bartlett's test of sphericity: It is a test statistic used to examine the hypothesis that the variables are uncorrelated in the population. In other words, the population correlation matrix is an identity matrix; each variable correlates perfectly $(r=1)$ with itself but has no correlation $(r=0)$ with the other variables under study.

Kaiser-Meyer-Olkin (KMO): KMO measure of sampling adequacy is a measure of sampling adequacy, an index used to examine the appropriateness of factor analysis. The KMO value varies from 0 to 1 . High values (between 0.5 and 1.0) indicate factor analysis is appropriate. Generally, a KMO > 0.5 is desirable. Here $\mathrm{KMO}=0.788$, which is acceptable as KMO between $0.7 \& 0.8$ is considered good.

Communality: The amount of variance shares with and portion of variance explained by common factors referred to as communality. This term may be interpreted as a measure of "uniqueness."A low communalities figure indicates that the variable is statistically independent and cannot be combined with other variables. The extracted communalities greater than 0.5 , are acceptable for the variables.

Variance explained: For this, an analysis of the Eigen values is required, which represents the total variance explained by each factor. Percentage of variance is the total variance attributed to each factor. The analysis is carried out at Eigen Value $=1$ to find the numbers of factors extracted statistically.

Model Fitness Test: Residuals are the difference between the observed correlations, as given in the input correlation matrix, and the reproduced correlations, as estimated from the factor matrix. Residual $<50 \%$ is acceptable and model is considered as fit.

The Correlation coefficient (r): This test indicates the closeness of the variables with each other. The value of $r=1.0$ indicates there exists perfect positive correlations between variable examined. The value of $r=-1.0$ signifies existence of perfect negative correlation and when $r=0.0$ indicates there is no correction between variables considered.

The factor loading: The value of factor loading 0.50 and more are considered as significant for the statistical analysis.

Table -1: Factor loadings and measures

\begin{tabular}{|c|c|l|}
\hline Sr.No. & Factor Loadings & \multicolumn{1}{|c|}{ Measures } \\
\hline 1 & More than 0.50 & Very Significant \\
\hline $\mathbf{2}$ & $\mathbf{0 . 5 0}$ & Significant \\
\hline 3 & 0.40 & More Important \\
\hline 4 & 0.30 & Important \\
\hline
\end{tabular}

\section{LIMITATIONS OF THE STUDY}

The problems in data collection were many like:

- Non-availability of some secondary data.

- Responses with reservation caused limited co-operation from some of the respondents.

- The investigator was thought to be industry - agent or government authority in spite of avowal was given, so extracting information was difficult initially, too much time was consumed in convincing them for the purpose of the study.

- The time factors, poor awareness of some respondents were other limitations.

- The supervisors and technicians were scared about the workers' disclosing problems they are facing at workplace.

- Lower education, language problem and lack of freedom to disclose the facts were major constraints to the workers.

\section{FACTORS NAMING AND ASSESSMENTS}

Table-2 shows the number of factors extracted are three with 69.708 total variance explained and Eigen value $=1.025$. All the tests confirmed the appropriateness of factor analysis including reliability of the questionnaire. 
Table- 3 represents the factor wise grand mean satisfaction Factor 3, the score is highest and it is 3.8708 . This indicates that respondents are more satisfied with productivity determinants for increasing productivity. Least score 2.8051 is for factor 1 . This indicates that respondents are less satisfied with productivity incentives. That shows the lacking part of the role played by various incentives from the employers. Remaining Factors 2, the mean score are between these two limits are 2.9423 represents between Not Sure (03) and disagree (02), but respondents are more inclined towards not sure on Likert Scale: Strongly agree (05), Agree (04), Not sure (03), Disagree (02) and strongly disagree (01).
The Chi-Square $\left(\chi^{2}\right)$ Test It assists us in determining whether a systematic association exists between the two variables. It helps us to understand how one variable relates to another variable, statistics are available for examining the significance and strength of the association [12].

\section{Hypotheses:}

$\mathrm{H}_{01}$ : Feelgood has no relation with productivity improvement

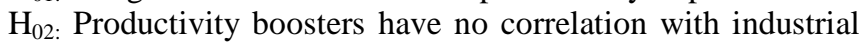
productivity.

$\mathrm{H}_{03}$ : Productivity determinants have no correlation with industrial production.

Table-2: The results of statistical analysis

\begin{tabular}{|c|c|c|c|c|c|c|c|}
\hline \multirow[t]{2}{*}{ Var } & \multirow[t]{2}{*}{ Attribute } & \multicolumn{3}{|c|}{ Factor } & \multirow{2}{*}{$\begin{array}{l}\text { Factor } \\
\text { Score }\end{array}$} & \multirow{2}{*}{$\begin{array}{l}\text { Communalities } \\
\text { Extraction }\end{array}$} & \multirow[t]{2}{*}{ Cronbatch's Alpha } \\
\hline & & 1 & 2 & 3 & & & \\
\hline V2 & Remuneration & 0.707 & & & \multirow[t]{3}{*}{1.029} & 0.656 & 0.704 \\
\hline $\mathbf{V 3}$ & Working hours & 0.856 & & & & 0.834 & 0.676 \\
\hline V4 & Working Condition. & 0.863 & & & & 0.855 & 0.678 \\
\hline V6 & Chances of promotion. & & -0.592 & & \multirow[t]{4}{*}{1.679} & 0.635 & 0.857 \\
\hline V7 & Teamwork & & 0.670 & & & 0.699 & 0.696 \\
\hline V10 & Management policies. & & 0.840 & & & 0.777 & 0.702 \\
\hline V11 & Work culture. & & 0.761 & & & 0.741 & 0.690 \\
\hline V1 & Feel Proud. & & & 0.615 & \multirow[t]{5}{*}{3.452} & 0.582 & 0.733 \\
\hline V5 & Housekeeping. & & & 0.812 & & 0.679 & 0.732 \\
\hline V8 & Training & & & 0.856 & & 0.753 & 0.728 \\
\hline V9 & Job rotation. & & & 0.519 & & 0.540 & 0.708 \\
\hline V12 & Living standard. & & & 0.650 & & 0.614 & 0.740 \\
\hline \multicolumn{2}{|c|}{ No. of variables associated } & 03 & 04 & 05 & & & \\
\hline \multicolumn{2}{|c|}{ Eigen Value } & 5.233 & 2.106 & 1.025 & & & \\
\hline \multicolumn{2}{|c|}{ Variance Explained } & 24.042 & 47.540 & 69.708 & & & \\
\hline \multicolumn{7}{|c|}{ Overall Scale Cronbatch's Alpha(Reliability Statistic) } & 0.788 \\
\hline
\end{tabular}

Table -3: Factor naming and grand mean of each factor

\begin{tabular}{|c|l|l|c|c|c|}
\hline Factor & \multicolumn{1}{|c|}{ Factor given name } & \multicolumn{1}{|c|}{$\begin{array}{c}\text { Variables associated } \\
\text { with each factor }\end{array}$} & $\begin{array}{c}\text { No. of } \\
\text { Variables }\end{array}$ & $\begin{array}{c}\text { Grand } \\
\text { Mean }\end{array}$ & $\begin{array}{c}\text { Assessment based on } \\
\text { grand mean } \\
\text { (Between })\end{array}$ \\
\hline 1 & Feel good & $\begin{array}{l}\text { V2(0.707),V3(0.856), } \\
\text { V4(0.863) }\end{array}$ & 03 & 2.8051 & Not sure \& Disagree \\
\hline 2 & Productivity boosters & $\begin{array}{l}\text { V6(-0.592),V7(0.670), } \\
\text { V10 }(0.812), V 11(0.761)\end{array}$ & 04 & 2.9423 & Not sure \& Disagree \\
\hline 3 & Productivity Determinants & $\begin{array}{l}\text { V1 }(0.615), V 5(0.812), V 8(0 . \\
856), V 9(0.519), V 12(0.650)\end{array}$ & 05 & 3.8708 & Not Sure \& Agree \\
\hline
\end{tabular}


Table- 4: Feel good

\begin{tabular}{|c|l|c|c|c|c|c|c|c|}
\hline Sr. No. & \multicolumn{1}{|c|}{ Variables } & $(\mathbf{0 5})$ & $\mathbf{( 0 4 )}$ & $\mathbf{( 0 3 )}$ & $\mathbf{( 0 2 )}$ & $\mathbf{( 0 1 )}$ & Total & $\begin{array}{c}\boldsymbol{\chi}^{\mathbf{2}} \text { at df } \mathbf{d} \text { ( } \\
\mathrm{CV}=52.52, \mathrm{P}<0.0001 \\
\mathrm{TV}=15.507, \mathrm{LSF}=0.05\end{array}$ \\
\hline 1 & Remuneration & 2 & 14 & 24 & 15 & 10 & 65 & \\
\hline 2 & Working hours & 2 & 28 & 1 & 29 & 5 & 65 & \\
\hline 3 & Working condition & 2 & 27 & 1 & 25 & 10 & 65 & \\
\hline
\end{tabular}

$\chi^{2}=$ Chi-square, $\mathrm{df}=$ Degree of freedom, $\mathrm{CV}=$ Calculated value of Chi-square test, $\mathrm{TV}=$ Table value, LSF =Level of significance

The "feel good" has positive relation. The employees are divided on the "feel good" in the organization where they are serving. Since, $\chi_{\mathrm{cv}}{ }^{2}=52.52>\chi_{\mathrm{tv}}{ }^{2}=15.507$, it has mentioned that the "feel good" is highly required to make employees more satisfied and hence, the company more productive.

Table- 5: Productivity boosters

\begin{tabular}{|c|c|c|c|c|c|c|c|c|}
\hline Sr. No. & Variables & (05) & (04) & (03) & (02) & $(01)$ & Total & \multirow{5}{*}{$\begin{array}{c}\boldsymbol{\chi}^{\mathbf{2}} \text { at } \mathbf{d f}=\mathbf{1 2} \\
\mathrm{CV}=89.46, \mathrm{P}<0.0001 \\
\mathrm{TV}=21.026, \mathrm{LSF}=0.05\end{array}$} \\
\hline 1 & Chances of promotion. & 12 & 25 & 20 & 4 & 4 & 65 & \\
\hline 2 & Teamwork & 3 & 7 & 47 & 6 & 2 & 65 & \\
\hline 3 & Management policies. & 2 & 7 & 31 & 19 & 6 & 65 & \\
\hline 4 & Work culture. & 2 & 6 & 19 & 31 & 7 & 65 & \\
\hline
\end{tabular}

$\chi^{2}=$ Chi-square, $\mathrm{df}=$ Degree of freedom, $\mathrm{CV}=$ Calculated value of Chi-square test, TV=Table value, LSF =Level of significance

The "productivity boosters" has positive relation. The some of the respondents were in agreement, majority of respondents were not sure and only few respondents were not in favor of the productivity boosters existed there in the organization where they are serving. Since, $\chi_{\mathrm{cv}}{ }^{2}=89.46>\chi_{\mathrm{tv}}{ }^{2}=29.026$, it has mentioned that the "productivity boosters" are highly required to make organization more productive.

Table-6: Productivity determinants

\begin{tabular}{|c|c|c|c|c|c|c|c|c|}
\hline $\begin{array}{l}\text { Sr. } \\
\text { No. }\end{array}$ & Variables & (05) & (04) & (03) & (02) & (01) & Total & \multirow{6}{*}{$\begin{array}{c}\boldsymbol{\chi}^{\mathbf{2}} \text { at } \mathbf{d f}=\mathbf{8} \\
\mathrm{CV}=157.20, \mathrm{P}<0.001 \\
\mathrm{TV}=26.296, \mathrm{LSF}=0.05\end{array}$} \\
\hline 1 & Feel Proud & 8 & 57 & 0 & 0 & 0 & 65 & \\
\hline 2 & Housekeeping & 6 & 54 & 4 & 1 & 0 & 65 & \\
\hline 3 & Training & 11 & 46 & 7 & 1 & 0 & 65 & \\
\hline 4 & Job rotation. & 5 & 9 & 47 & 3 & 1 & 65 & \\
\hline 5 & Living standard. & 18 & 28 & 19 & 0 & 0 & 65 & \\
\hline
\end{tabular}

$\chi^{2}=$ Chi-square, $\mathrm{df}=$ Degree of freedom, $\mathrm{CV}=$ Calculated value of Chi-square test, TV=Table value, LSF =Level of significance

The "productivity determinants" has positive relation. The majority of respondents were in agreement with the "productivity determinants". Few respondents were not sure and very few were not agree with"productivity detemininents", existed there in the organization where they are serving. Since, $\chi_{\mathrm{cv}}{ }^{2}=157.20>\chi_{\mathrm{tv}}{ }^{2}=26.296$, it has mentioned that the "productivity determinants" are highly required to make organization more productive. 
All the three null hypotheses are rejected and "feel good", Productivity boosters" and "productivity determinants" are very mush essentials in the interest of the individual employee as well as organization as a whole.

\section{CONCLUSIONS AND DISCUSSIONS}

In this case study respondents were all workers of the organizations. They responded with little hesitation. The overall feeling judged that lot more should be done for their job satisfaction which would bring out more potentials from them. It will be mutual benefits of both .It is suggested to carry out more such study to extract what is what in the benefits of the employers and employees of the industries of the estate under consideration. Happy workers will bring happiness for the all. Productivity determinants considered here are of vital important for organizations

\section{ACKNOWLEDGEMENTS}

In pursuing research work, we have received help and support from all corners. We convey sincere thanks to all of them; it may not be possible to personalize each and every one. However, we express sincere gratitude to all of them: Sardar Patel University, Vallabh Vidyanagar. Industry Commissioner of District Industries Centre, Anand for permitting to use all the records and related literatures of industrial scenario of Anand district. Resident District Collector, Anand and staff for providing related literatures of industrial scenario and records of Gujarat state. Executives of Amul Dairy, Anand for their help to furnish details and permit visit of AMUL plants, for the study of their performance enhancement programme. Rupal Books Stall, Vallabh Vidyanagar for timely procurement of source materials, books, and references at ease and speed for literature survey for research work. Secretariat of V. U. Industries Association and all industrialists, employees, for their all time help for information and permission to use all available data, references.

\section{REFERENCES}

[1] Goal, Bharat and Dewan, Bhushan (2011). Factors affecting consumer preferences of shopping at organized retail stores in Punjab' Journal of Engineering, Science and Management Education, NITTTR, Bhopal. 4, 44-49.

[2] Heizer,Jay, Render Barry, (1999), Operations Management, Prentice-Hall, Int. New Jersey.

[3] Jani, H. J., (2004). Ph.D. Thesis, Quality Management in Indian Companies through ISO 9000, Sardar Patel University. Vallabh Vidyanagar.

[4] Joseph,A.GliemandRosemary .Glien(2003)Calculating, Interpreting, and Reporting Cronbach'sAlpha Reliability Coefficient for Likert-Type Scales,Midwest Research ro Practice Conference in Adult Continuing and Community.
[5] Jan Stringer,Dr., "factors that affect Employee's productivity" ,http://www.nbrii.com/employee-survey white papers,pp.1-2,2013.

[6] Malhotra Naresh K.,(2009). Marketing Research- an Applied Orientation, fifth edition, Pearson, New Delhi.

[7] Nargundkar Rajendra (2005). Marketing Research-Text and Cases, Tata McGraw-Hill Pub., New Delhi.

[8] Pandya,K. J. (2010). Ph.D.Thesis, Consumer Behaviour in Two Wheeler Industry: A case study of Motorcycle users in the state of Gujarat, Sardar Patel University, Vallabh Vidyanagar.

[9] Pankhania, T. B., Modi,V. K., (2011), The Factors influencing Target Market criteria: A survey conducted inindustries at Vitthal Udyognagar in Anand District ofGujarat State, India,International Journal of IndustrialEngineering \& Production Research, September2011,Volume 22,Number3, pp.213-220.

[10] Pankhania,T.B., (2011), Ph.D. Thesis, Industrial productivity scenario and potentiality in VitthalUdyognagar in Anand district of Gujarat, India, Sardar Patel University, Vallabh Vidyanagar, Gujarat.

[11] Pankhania,T.B.\&Modi V.K. (2013), Impact of various aspects on Industrial Performance enhancing Productivity. International Journal of Engineering and InnovativeTechnology,Feb.2013 Vol.2,Issue-8,166-171.

[12] Rahman A.,Kalam A., Rahman,M., "The Influence of service Qouality and Price ON Customer Satsfaction: An Empirical Study on Restaurant Services In Khulna Division",IndustrialEngineering Letters,Vol.2,No.2,2012,pp.25-32.

[13] Rinalini Pathak Kakati and U R Dhar(2002), Competitive Strategies and New Venture Performance, Vikalpa,The Journal for Decision Makers, IIM of Management, Ahmadabad, India, 27(2),19-34.

[14] Seth, Anita, Momaya K, Gupta (2008). Managing the Customer Perceived Service Quality for Cellular MobileTelephony: An Empirical Investigation, Vikalpa, The Journal for Decision Makers, Indian Institute of Management, Ahmadabad, India, 33(1), 19-34.

[15] Sharma, K. V. S., (2006). Statistics Made Simple. Do it yourself on PC". Prentice-Hall of India, New Delhi.

\section{BIOGRAPHIES}

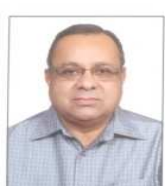

Dr. T. B. Pankhania, Associate Professor in Mechanical Engineering and Head, Workshop at B.V.M. Engineering College, Sardar Patel University, Vallabh Vidyanagar. He obtained his B.E. (Mech), M.E. (Mech), and Ph.D. from Sardar Patel University (SPU); Vallabh Vidhyanagar.His profile includes a stint of over 36 years of experience. His current areas of research include "Industrial performance leading to higher productivity. He has published his 18 research papers in national and international journals and presented 6 research papers in International conferences. He authored one book on Engineering Mechanics. tbp@sify.com 
Prof. Akil H. Jariya ,Assistant Professor in Production Engineering at B.V.M. Engineering College, Gujarat Technological University, Ahmadabad; He obtained his B.E. (Mech.) from Bhavnagar University, Gujarat and M. Tech. (Mech.) from Nirma University, Ahmadabad, Gujarat. His current areas of interest are $\mathrm{CAD} / \mathrm{CAM}$, Industrial Engineering and Managing Project. jariya_akil@yahoo.com

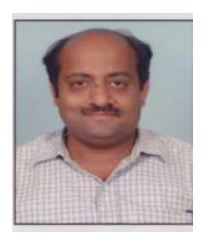

Mr. V. K. Modi, Lecturer in Mechanical Engineering at B \& B Inst. of Technology, Vallabh Vidyanagr. He obtained his master degree from M.S.University, Baroda. His areas of the interest are CAD/CAM and Industrial Engineering. He has 20 years of teaching experience. He has published 7 research papers in National and International Journals and presented 8 research papers in international conferences. E-mail:modi_vinit@yahoo.com 